\title{
¿Qué falta en el deseo?
}

\section{What's missing in desire?}

\author{
José L. SERRANo Ribeiro \\ (Universidad Nacional de Educación a Distancia)
}

Recibido: 28/03/2012

Aceptado: 07/11/2012

\section{Resumen}

Tanto el proceso metafórico como el interpretativo consisten en tomar algo extraño como algo familiar en función de la perspectiva que la fuerza del deseo propone. Partiendo de este supuesto intentaremos mostrar en este trabajo que lo que falta en el deseo, más que el objeto, es una relación interactiva, es decir, el vínculo por el que ese supuesto objeto faltante se podría abrir a la experiencia hermenéutica de tomar algo como algo. Y para ello seguiremos las consecuencias que se derivan de la pregunta por la relación imposible que formuló Leclaire en su artículo sobre la realidad del deseo. Si se pueden concebir dos elementos sin que exista entre ellos ninguna relación posible, lo que falta, entonces, no será ninguno de estos elementos sino el nexo hermenéutico que los podría conectar, y ahí es justamente el lugar en donde se instala el deseo.

Palabras clave: ausencia, deseo, hermenéutica, interpretación, sistema inconsciente.

\begin{abstract}
Both the metaphorical process and the interpretative one consist of taking something strange as something familiar depending on the perspective that the force of desire proposes. Starting from this supposition we will try to show in this work that what is missing in desire, more than the object, is an interactive relation, that is to say, the link which might open this supposed missing object for the hermeneutic experience of taking something as something. And to this purpose we will follow the consequences that stem from the question about the impossible relation that Leclaire formulated in his paper about the reality of desire. If one can conceive two elements that do not have between them any possible relation, what is missing at the
\end{abstract}


time will not be any of these elements but the hermeneutic link that might connect them, and this is exactly the place where one installs the desire.

Keywords: absence, desire, hermeneutics, interpretation, unconscious system.

\section{Introducción: presupuestos conceptuales}

La realidad para el ser humano puede ser entendida como el producto de un constante proceso de elaboración de lo otro para devolverlo convertido en algo propio. A este largo e interminable proceso lo llamamos interpretación, en donde cada nuevo elemento que se incorpora a la trama comprensora queda despejado de manera hermenéutica en función de lo ya retenido por ésta. Por ello, nos gusta citar la fórmula elemental de la interpretación que presentó Gadamer (2000, p. 32), pues resulta ser la noción más clara y concisa de lo que es interpretar: «Tomar algo por algo es interpretar». Para ilustrar el poder hermenéutico de esta célula básica, bien vale el caso de Marco Polo, quien «la primera vez que ve un rinoceronte escribe que ha visto un unicornio» (Ferraris, 2004, p. 93). Su interpretación consistió en tomar algo (un rinoceronte) por algo (un unicornio), en concebir un rinoceronte, animal que nunca había visto, bajo la acepción de un unicornio, animal fabuloso e inexistente pero del que ya tenía noticias procedentes de dibujos y relatos. La relevancia en la interpretación, como vemos, no reside en la verdad lógica ni en la identidad, pues «alli donde se quiere que tenga lugar el comprender no puede haber nunca sólo identidad» (Gadamer, 1998, p. 77), pero tampoco es una cuestión de inducción o deducción, y mucho menos de un encaje del particular en su universal correspondiente (cfr. Gadamer, 1994, p. 320). Lo que está en juego en hermenéutica no es verdadero o falso, satisface o no satisface, pertenece o no pertenece, verifica o no verifica, sino un hallazgo creativo de sentido entre los "algos" implicados, mediados por la función interpretativa "tomar ... por ...", que capta su energía del deseo.

La idea de Gadamer sobre la interpretación también puede presentar otras formulaciones alternativas, pero éstas siempre conservan el rasgo que enfatiza el intento de acercar lo desconocido a lo conocido. Fuera del ámbito de la hermenéutica filosófica hallamos una de estas fórmulas: «comprender consiste en reducir un tipo de realidad a otro» (Lévi-Strauss, 1970, p. 46). Y también en Freud (1974, v. 3, p. 139) se ve algo muy similar, en este caso al hilo de la dificultad que encierra la interpretación onírica: «esclarecer una cosa significa referirla a otra conocida». Pero si regresamos a la hermenéutica filosófica podemos ver la transformación del lema gadameriano: «la interpretación (...) convierte en algo propio lo que, en un principio, era extraño» (Ricoeur, 1999, p. 75). Es un proceso continuo de asimilación que 
podría ser ilustrado con la bola de nieve que va creciendo al rodar por la ladera de una montaña, lo mismo que el tejido lingüístico de la trama comprensora en cada acto hermenéutico de apropiación. Si interpretar es tomar algo por algo, valdrá también como ejemplo la manera en que un niño aprende nuevas palabras, es decir, siempre en función de las ya conocidas: «Schleiermacher (...) afirmaba que la hermenéutica es precisamente el modo en que un niño capta el significado de una nueva palabra» (Palmer, 2002, p. 122). De lo que se trata, pues, es de hacer familiar lo que antes era extraño. Esta idea la podemos encontrar en muchos lugares de la obra de Ricoeur, pero no es sólo él quien se ciñe a la nueva fórmula de hacer propio lo extraño. Gadamer ya había sido consciente de que lo relevante en hermenéutica era tender un puente entre lo propio y lo ajeno: «se da una polaridad entre familiaridad y extrañeza, en la que se basa la hermenéutica» (Gadamer, 1994, p. 68).

Además, partimos del supuesto de que la metáfora ejerce la misma función interpretativa que los dos esquemas hermenéuticos mencionados (el de Gadamer y el de Ricoeur), pues metaforizar no es más que tomar algo por algo, convertir lo extraño en familiar, ver y concebir algo en los términos de otra cosa según la perspectiva que el deseo promociona. Pero también la experiencia cotidiana nos demuestra que deseamos justamente lo que no tenemos, ese objeto que sólo se revela en virtud de su ausencia: queremos algo, en definitiva, porque nos falta. La etimología del término deseo sugiere esa especie de frustración que sentimos cuando algo brilla por su ausencia: «la palabra deseo (...) viene del vocablo latino 'de-siderare', cuyo primer significado es comprobar y lamentar que las constelaciones, los 'sidera', no den señas, que los dioses no indiquen nada en los astros. El deseo es la decepción del augur» (Lyotard, 1994, p. 121). El deseo está sostenido por la carencia, por el objeto faltante; pero más adelante veremos que, en realidad, lo que está ausente es más bien la relación que podría conectar una cosa extraña con otra familiar en el proceso que genera el vínculo hermenéutico, antes que el supuesto objeto ausente. Si Marco Polo no hubiese sabido nada en absoluto de unicornios, nunca podría haber tomado un rinoceronte por uno de ellos en su deseo de esclarecer la identidad del animal, y lo que hubiera fallado, en primer lugar, hubiera sido el nexo hermenéutico que el deseo no logró conectar con ningún objeto.

\section{La pregunta y el principio hermenéutico}

Tenemos, por una parte, los grandes mediadores especializados en crear nexos entre los elementos de nuestro universo de experiencias posibles: tomar algo por algo en la metaforicidad fundamental del lenguaje a la luz de las perspectivas que activa el deseo. Tenemos, además, aquello ignoto que aún no ha sido cosido a nada, por ausente, olvidado o reprimido, porque es inconsciente, porque es lo otro, o por- 
que no sabemos ni siquiera si existe. Y ahora nos preguntamos por la mediación imposible: "¿Es imaginable concebir dos elementos que no tengan entre si ninguna relación posible?» (Leclaire, 2000, p. 181). Del surrealismo aprendimos a saborear ciertas disonancias cognitivas que quizá pretendían tocar el nervio áspero de esta pregunta, pero no se trata de recurrir a casos extravagantes para dar cuenta de la relación imposible. Ortega (1966, p. 210), por su parte, también respondió de algún modo a esta cuestión: «los dos objetos más distintos que pueda imaginar tienen la nota en común de ser objetos de nuestra mente, de ser objetos para un sujeto». Pero tal ardid fenomenológico tampoco logra captar del todo la problemática de la relación imposible, porque no hablamos de aspectos comunes que hubiera que adivinar, sino de situar la fuerza del deseo en el "nexo con la alteridad fundamental", aparte de que el filósofo español considera que la relación de cualquier objeto con el sujeto siempre es de carácter consciente, debido a la naturaleza intencional de esa conciencia que retiene la realidad del objeto bajo una determinada perspectiva. Y para Davidson (2001, p. 253), cualquier cosa es como cualquier otra si elegimos adecuadamente el criterio de parentesco, pues «todo es como todo, interminablemente». De cualquier cosa es posible extraer algún rasgo para que sea considerado como vínculo de relación con otra, ya que si todo es como todo en algún sentido, también es diferente de todo en algún otro sentido. En efecto, decir que no hay dos cosas exactamente iguales es tan cierto como decir que no hay dos cosas totalmente distintas; pero el alcance de la pregunta que nos ocupa no hace sólo referencia a vínculos que se pudieran establecer por semejanzas o diferencias.

¿Qué significa la expresión "nexo con la alteridad fundamental"? Siempre es posible imaginarnos en la no muy extraña tesitura, por ejemplo, de estar intentando recordar algo que hemos olvidado (un sueño, una idea, una palabra o lo que íbamos a decir); nos esforzamos pero no damos con ello, pretendemos extender ese nexo cojo que perdió el núcleo de uno de sus extremos para ver si alcanzamos la pieza perdida, tanteamos a ciegas el camino recorrido volviendo sobre nuestros pasos para recuperar la hebra desaparecida; pero nada, sólo disponemos de un vínculo roto que conectaba dos polos, y ahora únicamente nos queda una ausencia, un lazo quebrado y un deseo en activo que apunta a esa alteridad convertida en tal por el olvido. Por lo menos en este ejemplo contamos con la posibilidad de que la memoria nos devuelva el objeto extraviado, pero en otros casos la cosa se complica, ya que la constelación de singularidades se nos escapa por completo: no nos hacemos cuestión de que tengamos que establecer ningún nexo, no sabemos que falta algo y tampoco se nos hace consciente el deseo que va tras el nexo. Sólo sabemos que la interpretación (la actividad lingüística especializada en establecer nexos) es el modo de ser del sujeto, que siempre nos falta algo y que hay un inconsciente que es la casa del deseo (y de los objetos perdidos). 
La pregunta a examinar es la que planteó Leclaire: ¿se pueden concebir dos elementos sin ninguna relación entre sí? Existe un principio hermenéutico según el cual todo enunciado puede ser entendido como la respuesta a una pregunta. Este principio se atiene al esquema de tomar algo por algo, y se puede encontrar en varios lugares de la obra de Gadamer. Veamos algunos: «no hay ningún enunciado que no se pueda entender como respuesta a una pregunta» (Gadamer, 1994, p. 219). Aquí acentúa el carácter primigenio del fenómeno vital hermenéutico, al quedar todo enunciado atrapado genéticamente en la fuente original de una pregunta que lo segrega y modela. En otros sitios recalca la posibilidad de que la solución a una pregunta pudiera pasar, tal vez, por una manifestación en su sentido más genérico, es decir, no ya una afirmación proferencial sino una obra de arte, un poema, un sueño, un síntoma, una ley jurídica o una traducción, ya que habla de una manifestación y no sólo de un enunciado: "cualquier manifestación ha de interpretarse como respuesta a una pregunta» (Gadamer, 1998, p. 69). Otra versión del principio insiste en que no hay otro medio de comprender una afirmación si no se descubre el interrogante implícito al que contesta: «la única vía para entender un enunciado consiste en obtener la pregunta desde la cual el enunciado es una respuesta» (Gadamer, 1981, p. 75). Y para acabar veamos otra forma más del principio que enfatiza la posibilidad de que el objeto de comprensión sea el "otro": «siempre que se quiera comprender a otro (...) debemos preguntarnos cuál sería la pregunta respecto a la cual esta o aquella manifestación lingüistica constituiría la respuesta» (Gadamer, 1998, p. 228).

Pero la cuestión no es tan sencilla. No se trata, por ejemplo, de pasar mecánicamente del juicio "me conozco a través del otro", a la pregunta obvia " $¿ a$ través de quién me conozco?". Lo que pretende mostrar este principio es la prioridad lógica de la pregunta sobre el juicio, la antecedencia metodológica del problema con respecto a su solución, como hizo Deleuze $(1987$, p. 12): «el problema tiene siempre la solución que merece en función de la forma en que se plantea». Sería absurdo que alguien se embarcara en un juicio del tipo "primero hay que suturar las arterias principales y luego las adyacentes", si no fuera un cirujano para quien esta cuestión es de su incumbencia. Si toda afirmación puede ser entendida como respuesta a una pregunta es debido a que «toda pregunta tiene su motivación» (Gadamer, 1994, p. 59), es decir, no aparece de manera aislada ni se genera aleatoriamente. Todo enunciado halla su horizonte de sentido en el ámbito temático del que procede (prejuicios, conocimiento de fondo, intereses prácticos, perspectivas usadas). Si toda pregunta tiene su propia motivación y alcance, será relevante investigar la dialéctica común en la que están involucradas preguntas y respuestas, pues del mismo modo que a toda afirmación le corresponde su pregunta, también «toda pregunta es a su vez respuesta» (Gadamer, 1994, p. 58). 
Recordemos que estamos examinando la pregunta del discípulo de Lacan: ¿es imaginable concebir dos elementos que no tengan entre sí ninguna relación posible? Se trata de una pregunta pero, como ahora sabemos, también puede ser tomada como una respuesta. No se nos pide un sí o no de modo categórico, al menos de primeras, sino que consideremos la posibilidad de tal relación imposible, que nos hagamos cargo de que no todas las relaciones están esclarecidas a priori. La pregunta ya indica un camino, porque «la interpretación se moldea mediante la pregunta con la que el intérprete enfoca el tema.» (Palmer, 2002, p. 92). Quizá no sea imaginable concebir dos elementos sin relación posible, pero esto nos puede inducir a pensar que sí podrían existir en un determinado registro con arreglo a una perspectiva. Intentemos, pues, enfocar la pregunta como si fuera una afirmación, es decir, como una respuesta, tal y como nos aconseja el siguiente principio que retiene las dos caras hermenéuticas del asunto: «Todos los enunciados son preguntas. Pero esto no es todo. La pregunta con respecto a la cual todo enunciado es una respuesta está a su vez motivada; por lo tanto, en cierto sentido, toda pregunta es igualmente una respuesta» (Gadamer, 1981, p. 76).

\section{El inconsciente, el sueño y la necesidad de interpretar}

Si toda pregunta tiene sus motivaciones y puede ser entendida como una respuesta, será interesante conocer el trasunto desde el cual Leclaire formuló su pregunta. El contexto es el artículo de 1965, La realidad del deseo (Leclaire, 2000, pp. 169-195), y de las 26 páginas que ocupa, la pregunta está situada a mitad del escrito (p. 181). Quiere esto decir que tiene sus estímulos e implicaciones, ya la tomemos como pregunta o respuesta (a otra pregunta). Comienza examinando el deseo inconsciente, y para ello pone en relación el sistema inconsciente con el deseo, utilizando como medio el sueño. La pieza clave de las investigaciones de Freud sobre el sueño se concreta en la aseveración de que el sueño es la realización de un deseo, idea que recorre toda la obra de La interpretación de los sueños, aunque también se halla en otros sitios: «la circunstancia de ser el deseo el estímulo del sueño, y su realización el contenido del mismo, constituye uno de los caracteres fundamentales del fenómeno onírico» (Freud, 1998, p. 132); o también en su autobiografía intelectual: «el sueño es la realización (disfrazada) de un deseo (reprimido)» (Freud, 1969 , p. 63). No olvidemos que la génesis, naturaleza y función del sueño consisten en activar un dispositivo psíquico que intenta evitar las excitaciones que pudieran perturbar el descanso diario, y la manera que disponemos para suprimirlas es recurriendo a la satisfacción alucinatoria de un deseo.

Entonces, ¿cómo es que si el sueño pretende suprimir los estímulos psíquicos residuales admite una actividad tan intensa, aunque sea de carácter alucinatorio?: 
«el más fiel y discreto de los vigilantes nocturnos habrá de verse obligado a producir algún ruido al perseguir a aquellos que con sus escándalos hubieran perturbado nuestro descanso en grado mucho mayor» (Freud, 1998, p. 132). Y suele ocurrir que más que cumplir un deseo, lo pretende sin lograrlo; escribe un guión pero el desenlace no cubre las expectativas, aunque lo relevante es la acción desplegada en la tentativa: "puede suceder que la elaboración onírica no consiga crear plenamente una realización de deseos (...). Si el deseo no ha sido satisfecho, no por ello la intención deja de ser laudable» (Freud, 1998, p. 226). Para ilustrar este aspecto del sueño como realizador de deseos, Leclaire recurre a uno de Freud, el de la monografía botánica (ver Freud, 1974, v. 2, pp. 8-30), donde las peripecias de la alcachofa, el placer sentido de pequeño al deshojar las páginas de un libro de botánica, la Biblia, el herbario, su amor a los libros (rata de biblioteca), y el reproche de su padre por no dedicarse a cosas de más provecho económico y reconocimiento social, muestran el deseo que encubre el sueño: "que él es un hombre capaz de hacer un trabajo de valor, un trabajo fecundo, (...) que él no es "un fruto seco"» (Leclaire, 2000 , p. 172). Elementos que parecen inocentes se utilizan en la elaboración onírica para figurar junto a ellos otros más relevantes que tienen que ver con la culpa, el reproche y el deseo de demostrar que su trabajo es importante y digno de mérito.

Ahora habrá que conectar la pieza maestra del sueño como realizador de deseos con otra no menos esencial que dice que el sueño es el mejor acceso al inconsciente: «la interpretación onírica es la vía regia para el conocimiento de lo inconsciente» (Freud, 1974, v. 3, p. 230) aunque, como dice Lacan, esto no significa que el sueño sea el inconsciente mismo. Podemos ver así cómo el sueño es capaz de abrir una vía hacia el inconsciente y mostrar, aunque sea deformadamente en aquellos decorados y objetos de apariencia inocua, los deseos en plena acción. Las pistas están constituidas por el texto del sueño, es decir, por un relato reelaborado del suceso alucinatorio que presenta elementos singulares que habrá que recomponer, y encontrar en ellos un nexo posible (o imposible) y un sentido. Y aquí comienza el apartado segundo del artículo de Leclaire, que titula El inconsciente es un discurso radicalmente "otro" (p. 173): otros elementos, otros procesos, otras conexiones, otros tiempos y lugares, otras categorías. Al presentar la alteridad radical del inconsciente pretende dar cuenta de "otro" modo distinto de ser, en donde el pronombre "otro" mienta el absoluto desfase de ese modo "alter-ado" de ser del inconsciente con respecto al consciente.

El inconsciente freudiano es otra cosa, otra palabra, otro discurso, otra operación, otra ley, en sentido drástico, sin medida con lo que posee lógica y sentido; es la estructura fundamentalmente inconmensurable con lo que podemos conocer por tenerlo atado hermenéuticamente. Y como ejemplo, Leclaire cuenta la historia de un recién ingresado en un psiquiátrico, diagnosticado de melancolía casi catatónica después de los siguientes incidentes: el paciente se mostraba pensativo y dócil pero 
muy poco comunicativo, y cuando estaban haciendo su habitación se tira por la ventana. Gracias a la poca altura no sufre lesiones de importancia y a las dos semanas recobra la palabra. En realidad, no quería suicidarse, la vida es demasiado bella como para perderla, sólo que vio pasar unos aerolitos maravillosos por el cielo azul con luces de colores y pretendió atrapar el último para marchar al espacio con él: «esta historia hace resaltar lo que puede querer decir "otro discurso”, otro, radicalmente otro sin relación de sentido con el primero» (Leclaire, 2000, p. 174). No se trata de lo que está detrás del escenario o la cara oculta de algo, tampoco es un contrapunto musical en una fuga, ni tan siquiera el texto que se puede leer escogiendo bajo un determinado algoritmo ciertas letras.

El inconsciente freudiano se parece más a la pintura que fue cubierta por otra en un lienzo, o a esa música de rock que suena detrás de una obra clásica en una emisora mal sintonizada y con la radio baja de pilas: «el inconsciente no es el mensaje, ni siquiera extraño o cifrado, que intentamos leer en un viejo pergamino: es "otro texto", escrito por debajo, que es preciso leer (...) con ayuda de un revelador» (Leclaire, 2000, p. 175). Esta heteronomía fundamental entre consciente e inconsciente, es ilustrada por Freud considerando la contraposición entre un yo y otra persona. Si queremos entender en nuestro propio ser ese hiato que se produce entre los sistemas consciente e inconsciente, deberemos aplicar el mismo método: «todos los actos y manifestaciones que en nosotros advertimos, sin que sepamos enlazarlos con el resto de nuestra vida activa, han de ser considerados como si pertenecieran a otra persona» (Freud, 1993, p. 190). Es como si estuviéramos constituidos por una doble conciencia; una accesible al pensamiento, a la introspección y a la reflexión, y otra como si perteneciera a otra persona y, por tanto, extraña; por lo cual deberemos considerar que existen «dos estructuras radicalmente heteronómicas, para no decir antinómicas»(Leclaire, 2000, p. 176), que son el sistema consciente por un lado, y el inconsciente por otro.

Antes de describir el sistema inconsciente, Leclaire repara en el hecho de que la actitud natural del ser humano, tanto consciente como inconsciente, ante cualquier cosa desconocida pasa por intentar descubrir alguna correspondencia que la vincule con otra familiar. El espíritu hermenéutico de tomar algo por algo o de hacer propio lo extraño es el mismo que el de la estrategia de la araña, que teje su tela conectando puntos distantes; igual que el modo humano de ser, que sólo puede vivir interpretando, es decir, atando cabos y relacionado sin cesar. Porque interpretar no es algo reflexivo, sino el modo de ser constitutivo del ser humano. En efecto, el Dasein no tiene más remedio a cada instante que decidir su ser, lo que implica una interpretación de sí mismo y de los vínculos que le relacionan con su entorno, con su horizonte mundano poblado de entes, por lo que si no hubiera interpretación tampoco habría Dasein. O como dice Gadamer (1997, pp. 130-131), para quien estar en el mundo implica que todo lo que nos sale al encuentro es ya, por eso mismo, fruto de 
una interpretación: "la interpretación no es una actividad aislada de los seres humanos sino la estructura fundamental de nuestra experiencia en la vida. Siempre estamos considerando algo 'como' algo. Este es el dato primordial de nuestra orientación en el mundo, y no podemos reducirlo a algo más simple o inmediato»; y también Ricoeur (2003, p. 13): «comprender no es ya entonces un modo de conocimiento, sino más bien un modo de ser del ser que existe al comprender.»

En efecto, cualquier cosa tomada en consideración, por este mero hecho, se convierte en símbolo, pasa a ser un núcleo activo lingüístico y hermenéutico con el poder de apuntar a otra cosa; y esto significa que no puede existir nada en el mundo que carezca de algún significado para el ser humano: el cero absoluto semántico no existe, (Leclaire dirá que es justamente ahí, en esos vahídos hermenéuticos, en donde le gusta instalarse al deseo). Pero la defensa de esta tesis no sólo procede de la hermenéutica filosófica, también el existencialismo ha entendido que el modo de ser humano es una existencia sumida en la ineludible actividad interpretativa, tal y como dice Sartre (1973, pp. 23-24): «la comprensión no es una cualidad que le llegue desde fuera a la realidad humana, es su propia manera de existir». Y la perspectiva psicológica también reconoce la tendencia natural del ser humano a establecer relaciones hermenéuticas. Un organismo con facultades psíquicas maduras necesita para su estabilización vital un ensamblaje articulado, ya sea mal o bien fundado, con todo lo que sale a su encuentro; necesita transformarse en cada relación que sostiene con lo desconocido para convertirlo en algo con sentido para el yo: «existe en el psiquismo un principio de convergencia-coherencia cuya función principal es la de organizar un sentido, (...) ya que es vital para la supervivencia psíquica establecer vínculos» (Botella, 1997, p. 13). Ante cualquier aparente sinsentido, la actitud humana será la de anticipar una interpretación, probar un nexo significativo tomando algo por algo, construir algo familiar a partir de lo extraño. El talante interpretativo intentará tender un lazo que satisfaga el principio hermenéutico de convergencia para organizar un sentido, ya sea en el dominio mundano de los entes o en el campo intralingüístico: «llama la atención la tendencia de los sujetos a construir significados admisibles para todos los enunciados, incluidos aquellos sin sentido» (Gallego, 1996, p. 59).

\section{El inconsciente y el deseo: nexos y contrastes}

Un núcleo irreductible de singularidades sin posibilidad de trabazón no se podría dar más que en contraposición a un fondo donde lo habitual fuera el vínculo, la tela de araña que hace de nexo entre un algo y otro algo, la interpretación, la relación y el sentido: lo totalmente "otro" sólo puede ser concebible en la medida en que se destaca sobre lo "mismo", presentando así la lógica de su alteridad. Esto 
es importante porque nos permite establecer un correlato entre la alteridad fundamental y la falta, ya que si la lógica de la primera es generada por la discordancia que presenta con lo determinado hermenéuticamente, la lógica de la falta, en este sentido, vendrá respaldada por el fondo patente de lo recogido en la urdimbre comprensora, trama relacional hilvanada con el mismo hilo de deseo que echa de menos a la otra pieza que no aparece por ninguna parte. Falta la cosa y falta el nexo.

A partir de la lógica de la falta podemos emplazar el deseo, pero tengamos en cuenta que faltar debe ser entendido como un faltar con respecto al plexo mundano de relaciones. Y la cuestión es obvia: no se echa de menos cualquier cosa (nexo o elemento singular) en cualquier condición, proceso, función, estructura, tiempo, lugar o contexto. No echamos en falta, por ejemplo, a Einstein esquiando en la Luna. Un martillo o un coche muestran lo que son en función de la ausencia de algunos de sus componentes, como le sucede al "estado oculto de la salud", que sale a relucir precisamente en su falta, en el desequilibrio de la enfermedad: «el carácter de la comprensión se entenderá mejor no mediante un catálogo analítico de sus atributos, ni en la aparición completa de su propio funcionamiento, sino cuando se rompe, (...) cuando falta algo que debe tener» (Palmer, 2002, p. 92), como el lapsus, el olvido, el chiste, el sueño, la alucinación, los síntomas neuróticos, la fantasía o la metáfora, mediadores todos ellos que son puestos en acción por el deseo fraguado en lo inconsciente.

Veamos ahora los rasgos más relevantes del sistema inconsciente. Su núcleo está formado por representaciones pulsionales que aspiran a derivar su carga a un destino determinado, y cuando se activan varias mociones a la vez con distinto destino, se interfieren para establecer un fin intermediario, como ocurre en el sueño o en los síntomas neuróticos, que no son más que el producto de una transacción entre la aspiración de una moción pulsional y la resistencia que ejerce la censura. Esta movilidad de impulsos diversos (porque no se determinan entre sí), y coordinados (porque se dan transacciones en función de los fines), constituye el fundamento dinámico del sistema inconsciente. En éste reina el proceso primario, caracterizado por dos actividades: la de desplazamiento, por la que una carga de representación pulsional deriva su energía en otra; y la de condensación, por la que una moción recoge la carga de otras. También se caracteriza por ser alógico, pues obvia el principio de contradicción; atemporal, pues carece de ordenación cronológica; y estar vuelto de espaldas a la realidad, ya que lo que domina es el principio del placer (cfr. Freud, 1993, pp. 208-209).

Pero en esta somera descripción, Leclaire echa en falta una característica contraria a esa exagerada movilidad de investiduras, tan volátiles y variables. Se trata de investiduras de "excepcional fijeza" (p. 178) que hacen que ciertas cadenas inconscientes aparezcan de manera rígida e inmutable. Leclaire intentó describir el sistema inconsciente partiendo de la afirmación de Lacan de que está estructurado 
como un lenguaje, e identificó los dos mecanismos del proceso primario, el desplazamiento y la condensación, como correlatos de las figuras retóricas de la metonimia y la metáfora, respectivamente. Con ello pretendía establecer una imagen lingüística del sistema inconsciente para dar cuenta de esos productos de fabricación propia y de excepcional fijeza: en el discurso inconsciente suelen aparecer cadenas lingüísticas formadas por secuencias cortas, quebradas, circulares y repetitivas. En efecto, lo que no se puede recordar regresa de otro modo, disfrazado de impotencia hermenéutica y de insistencia rítmica: «cuando el sujeto se acerca demasiado a los recuerdos en relación con el núcleo patógeno inconsciente, faltan las asociaciones, la palabra se agota, se censura (...). La transferencia en su fase de resistencia, se transforma así en el lugar de la repetición de lo que para él constituye un obstáculo» (Adam, 2007, p. 132), como la mosca que se golpea una y otra vez contra el cristal. Esto quiere decir que los contenidos del inconsciente, además de presentar una gran capacidad para el intercambio de elementos susceptibles de ser cubiertos por las investiduras, también pueden cristalizar en cadenas sólidas, entrecortadas e inamovibles que se repiten sin cesar. La ilustración clínica que propone Leclaire a este respecto es el sueño de "la sed de Philippe" o el sueño del "Licorne" (unicornio), en donde a partir de la serie entrecortada integrada por los elementos "Liliplage - soif-sable-peau-pied-corne", la palabra "Licorne" emerge a partir de la contracción de los dos extremos de la cadena: «De este modo podía (...) ver el inconsciente, que en cierto modo así aparece en esta cadena enigmática, heteróclita y heterogénea como el animal fabuloso. En esta cadena de palabras, absurda, jeroglifica, incongruente, pero insistente e inconmovible, tenemos una especie de cifra ciega de la singularidad que se repite» (Leclaire, 2000, p. 179).

La tercera parte del artículo, (La ficción del "puro ser de deseo", o la coherencia del sistema inconsciente) empieza con un interrogante del que ya sabemos sus precedentes: «¿de dónde viene la coherencia propia y, en cuanto a algunos de sus elementos, indestructible del sistema inconsciente?» (Leclaire, 2000, p. 180). ¿O habría que preguntar mejor por la adherencia de lo inconsciente y sus contenidos? Quizá convenga recordar otro antecedente con respeto a la indestructibilidad del inconsciente: «El respeto que el sueño mereció a los pueblos antiguos se hallaba fundado en una exacta estimación psicológica de lo indestructible e indomable existente en el alma humana» (Freud, 1974, v. 3, p. 234); donde estas investiduras de excepcional fijeza en algunas cadenas inconscientes ya habían sido descritas por Freud bajo los epígrafes de la contrainvestidura o la barrera de la represión. En lo inconsciente nada acontece, nada se procesa, nada se pierde, nada comienza y nada concluye, nada se determina; y sus formaciones, tanto a nivel tópico como dinámico, están expuestas a la constancia de un fondo de lecho pulsional indestructible: «los deseos inconscientes permanecen siempre en actividad. Representan caminos siempre transitables en cuanto quiere servirse de ellos un quantum de excitación. 
La indestructibilidad constituye una de las singulares peculiaridades de los procesos de este género. Nada hay que pueda ser llevado a término en lo inconsciente, donde no hay tampoco nada pasado ni olvidado» (Freud, 1974, v. 3, p. 202).

Pretendíamos coherencia donde parece que sólo rige el sinsentido, pero la falta de lógica, la inexistencia de vínculos cronológicos, la ausencia de criterio de realidad, la movilidad ilimitada de las investiduras y la tremenda esclerotización que presentan algunas secuencias quebradas inconscientes que a veces acceden al lenguaje, no son los únicos factores que definen una instancia singular de incoherencia. Es más, si quisiéramos «concebir un sistema cuyos elementos están ligados entre sí precisamente por la ausencia de todo vínculo» (Leclaire, 2000, p. 181), no tendríamos más que establecer comparativamente algunos sistemas intracoherentes, menos uno. Por ejemplo, imaginemos cuatro viñetas que contienen estos elementos: en la primera, un perro, un gato, un pájaro y una ballena; en la segunda, un hombre delgado a caballo ensartando una lanza, unos molinos de viento, un rebaño de ovejas, y otro hombre regordete de baja estatura subido a un burro; en la tercera, las palabras "mano", "mesa", "mono" y "momia"; y en la cuarta, un picaporte, un tapón, un naipe y un cigarrillo. Y ahora hilamos todo lo fino que podamos: todos son animales en la primera, en la siguiente el nexo es la historia de Don Quijote, en la tercera todas las palabras comienzan por " $m$ ", ¿y en la cuarta? Miremos otra vez. Ahí están los cuatro elementos, son los mismos, no han cambiado, y auguran una insistencia como la de esas cadenas inconscientes de las que habla Leclaire. Si nos preguntaran cuál de las cuatro viñetas exhibe una relación incoherente, responderíamos sin dudar que la última. Descubrimos su unidad diferenciada en virtud de la heterogeneidad manifiesta de sus elementos. ¿No confirma tal unidad que ha habido un intento de conexión hermenéutica? ¿No se siente su coherencia justamente por la falta de coherencia? ¿No es la única viñeta que forma otra coherencia en contraste por carecer de ella? Se trata de la coherencia del vertedero, que consiste en que cada elemento se acumula allí al ser desplazado de su origen: todos han acabado allí porque no están en otro lugar, esa es su coherencia, esa es la ratio de su ensamblaje. Cada elemento de la última viñeta tiene sentido por sí mismo, pero no logramos concebir un sentido global, aunque el hilo del deseo tenga que esperar sin atreverse a coserlos: «este deseo (de reconstruir) -y vemos aparecer aqui el deseono impide que esos elementos se sostengan juntos, o para decirlo mejor, que estén soldados, pegados, precisamente por la ausencia de lazo» (Leclaire, 2000, p. 183).

El ejemplo de las cuatro viñetas es nuestro, pero el de Leclaire está tomado de un caso clínico, en el que tras horas de análisis, silencios prolongados, desvaríos y estornudos, el analizado llega a mostrar ese otro, que también es él, a través de un conjunto de puras singularidades. Algunos fragmentos sueltos que el paciente mostró al hablar, consiguieron abrirse camino en lo que parecía ser una cadena asociativa: el olor a un cuello de mujer a la vuelta de un paseo de primavera, la prosodia 
lenta de una voz grave que parece decir "ti” y que envuelve de cálida sonoridad la estancia, la franja aromática de una fragancia dulce a manzanas asadas; la contundencia y plenitud en el momento en que la mano toma una pelota, y un lunar sobre la piel. ¿Dónde está el nexo? Si el psicoanálisis, en su vocación de dotar de sentido a cualquier conjunto de objetos, encontrara el nexo entre tales elementos, estaría abocado a considerar que éstos no son los términos últimos e irreductibles del inconsciente, pues nos llevarían indefinidamente a otras viñetas con otros objetos e historias. Pero si tropezamos una y otra vez con el mismo grupo de puras singularidades, es que hemos tocado el nervio mismo del deseo, que se presenta como un vacío de sentido: «este sentimiento tan vivo que experimentamos (...) ante ese vacio de sentido, de un absurdo que es preciso paliar, este sentimiento que nos hace sentir en carne viva, (...) es el deseo. Es esta fuerza insuprimible la que sustenta dos (o más bien varios) elementos de pura singularidad, y vemos aquí que parece oponerse fundamentalmente al surgimiento de una significación, de un sentido. El deseo (...) parece estar entonces vinculado a la falta de nexo» (Leclaire, 2000, pp. 183-184).

Como vemos, hay un deseo que trenza los objetos en el acto hermenéutico de apropiación (sistema consciente), que es el mismo que se experimenta como nulidad de sentido, como expropiación del nexo ante lo radicalmente otro: esa oquedad, esa falta, ese no-ser, es el deseo (sistema inconsciente). Unas veces se disuelve y renueva en el avance simbolizador de la comprensión, y otras se detiene y embalsa. Unas veces cose, y otras es cosido; unas veces relaciona promoviendo vínculos, y otras es asociado a la falta de nexo: «el deseo moldea y es moldeado; interpreta a la vez y en tanto es interpretado; piensa, es pensado y da que pensar» (Sperling, 2001, p. 25). El deseo interpreta y es interpretado: postrados en el diván, la única esperanza de conocer nuestros deseos pasa por la acción del deseo del analista. Pero antes o después hemos de enfrentar esa falta de nexo, ese objeto perdido con el que supuestamente se conectaría. Y eso perdido es el objeto " $a$ " lacaniano, causa del deseo, cuyo significante es el falo (decimos significante y no significado, y decimos falo y no pene), cifra de la ausencia de lazo, esencia de la falta y «emblema de la diferencia por excelencia, irreductible: la de los sexos» (Leclaire, 2000, p. 189). Pero en Lacan el deseo es tratado en función del deseo del otro, y mientras que en la angustia patológica hay un desnivel entre el sujeto y el otro, porque el primero desconoce qué objeto " $a$ " representa para el deseo del otro, en las situaciones cotidianas el lazo del sujeto con el otro está siempre presente aunque no exento de una carencia permanente. Siempre hay algo que nos liga al prójimo, por lo menos porque somos semejantes a él, pero nunca del todo, pues hay diferencias, aunque existe un nexo angustiante que es el soporte del deseo y de la falta. Por eso, el objeto " $a$ " aparece en el artículo de Leclaire como lo irracional unitario por excelencia, como la aporía de un vínculo ausente, como la negación de la posibilidad conjuntiva del proceso hermenéutico, como la falta. 
Dos sistemas eran los que se enfrentaban, el consciente y el inconsciente; el primero, guardián del sentido, y el segundo, del sinsentido. Pero, como nos muestra Freud, estos dos sistemas no constituyen dos compartimentos estancos, sino que existen relaciones entre ambos (ver Freud, 1993, pp. 211-216): el representante de la pulsión que ansía descargar su investidura llega a convertirse en palabra, aunque sea fija, serial y repetitiva. Ningún diálogo es posible a menos que se ajuste al modelo lingüístico de la palabra. Si en lo inconsciente (sinsentido) cristalizó esa serie aporética de palabras rígidas, es que de algún modo dentro de la alteridad radical entre ambos sistemas existía una conexión lingüística capaz de petrificar los significantes como posibles portadores de sentido (consciente) o de sinsentido (inconsciente), porque al menos en esta diferencia se puede registrar la fuerza del deseo, aunque la situemos a veces como un vacío absoluto e ininteligible (la falta). Por eso, conviene subrayar «la heteronomía radical de lo consciente y de lo inconsciente» (Leclaire, 2000, p. 187). Cuando decimos que el signo está constituido por el significante y el significado, olvidamos que entender así el átomo semiótico es una abstracción conceptual lograda gracias al lenguaje. ¿Podemos imaginar en este baño lingüístico lo que sería algo exento de significante? En cuanto algo se considera sólo como significante disponemos ya el camino para el advenimiento de la palabra. ¿Constituye una ficción un significante así? Quizá, pero no menos, que la del puro ser del deseo o la de la incoherencia del inconsciente, por no decir también la del sentido o la de los deseos conscientes. El privilegio de la palabra comienza en la necesaria ficción ilocucionaria, por ejemplo, de investir a alguien como rey, y termina con la ficción perlocucionaria que hace que ese "rey" se crea que lo es: he aquí el deseo, la falta y la aporía.

Nos gustaría introducir una posibilidad con respecto al cumplimiento de un deseo de forma alucinatoria por el sueño. El sueño es la realización de algún deseo, pero a veces sólo es un intento porque no se consuma tal satisfacción. Ahora nos preguntamos: ¿no será que el sueño, más que realizar o intentar realizar un deseo, lo que hace es crearlo? Y no ya sólo el sueño, sino cualquier proceso de carácter lingüístico: ¿qué sucede con el sueño, la interpretación o la metáfora?, ¿expresan un deseo o lo crean? Si desatendemos el espíritu del psicoanálisis, quizá creamos que nuestros deseos actuales son nuevos, pero si tenemos en cuenta la indestructibilidad de los deseos inconscientes, tal vez consigamos amparar la idea de que lo que llamamos deseos recientes no son más que la forma actualizada de deseos arcaicos que dejaron su marca indeleble en las zonas más insospechadas de nuestra conducta y carácter. Estamos ante una transacción que no cesa de regresar en la transferencia, por eso lo difícil es saber si nuestros síntomas (y sueños, metáforas, ilusiones, miedos o sucesos aparentemente casuales) son nuevos o antiguos, si están reconstruidos a base de materiales viejos o si son una recreación de lo que mejor podría haber sido para inducir retrospectivamente una posibilidad alternativa que ya nunca se 
podrá dar, si no es a través de la reiteración que se renueva en la transferencia. ¿Qué perdimos ahí donde siempre volvemos?

Veamos lo qué dice Leclaire de la realidad del deseo: «El deseo es (...) esencialmente lo que subyace a dos términos que no reconocen ningún vínculo entre sí (los "elementos de pura singularidad"). Se puede decir (...) que esta fuerza o este cimiento del conjunto inconsciente, el deseo inconsciente propiamente dicho, está verdaderamente especializado -tal es su naturaleza- en las "ligazones imposibles"» (Leclaire, 2000, p. 187). El deseo es la energía que sustenta los elementos que no podrían ligarse de ningún otro modo: evanescencia lógica, temporal, de mediación y sentido, aunque solidificada en torno a cuatro niveles sobre el sujeto que lo particularizan y determinan: a) en el registro somático, donde la fuerza del deseo se interioriza como deseo del Otro, sin el que sería posible que el bebé sobreviviera, reteniendo sobre $\mathrm{su}$ cuerpo las mismas aporías que constituyen su inconsciente; b) en el nivel psíquico como relación imposible entre los dos sistemas (consciente e inconsciente), cuyos frutos estarán más cerca del puro deseo en la medida en que haya suficiente margen como para soportar la duda y evitar la interpretación compulsiva o de conveniencia; c) en el nivel de la elección amorosa, señal de la imposible relación entre los sexos, que se intentará solventar recurriendo a la recuperación imaginaria del objeto perdido: "sólo soy una mitad". "He aqui el deseo pensado en griego: intento angustioso de recuperar lo perdido, impulso de retorno al origen que, para el griego, estuvo - está- efectivamente allì» (Sperling, 2001, p. 100). Y d) en el horizonte teológico de la relación del hombre con su Dios, que expresa el último extremo de la paradoja de lo totalmente otro, otra relación imposible elevada a la máxima potencia. Como ocurría con el deseo, Dios está sostenido por la relación imposible, pues «Dios es el lugar de la no-relación» (Regnault, 1993, p. 13).

\section{La ausencia en el deseo y el deseo en la ausencia. Un hallazgo colateral}

Podría parecer, como dice Leclaire, que una presentación así del deseo inconsciente, sugiere que es algo impreciso y etéreo, pues no lograría proporcionar para cada uno sus experiencias irrepetibles, insustituibles y distintas, ni tampoco esos tropezones en las mismas piedras. Cada cual se siente único en virtud de este deseo que articula cada punto de vista y cada línea narrativa biográfica. Nuestro puesto está justamente en el lugar de nadie, porque si hubiera otro ya no lo podríamos ocupar; y ahí mismo saltan las chispas del sentido gracias a que tropezamos en otras partes del laberinto con cúmulos de sinsentido por los que no podemos transitar (ahí está la falta y el deseo): «El deseo inconsciente, en su imposible diálogo con el sentido, orienta y estructura para cada cual en su singularidad los elementos de 
su experiencia y los propios tiempos de su historia. Fija (...) los modos particulares de encuentro de cada cual (...) con el orden del mundo» (Leclaire, 2000, p. 189).

¿No es el psicoanalista un intérprete? ¿Se quedaría conforme con el hallazgo de una cadena fija sin encontrar el nexo? ¿Qué hacer con el cuello oloroso de mujer, la voz que decía "ti”, la franja aromática dulce, la plenitud de la mano al coger una pelota, y el lunar? Si no halla un vínculo tendrá que responder afirmativamente a la pregunta por la posibilidad de que existan algunos elementos que no tienen entre ellos ninguna relación. Son posibles las conjunciones de elementos para los que no hallamos ninguna relación, y la prueba está en que a veces no la encontramos. Pero lo importante de esto es descubrir hacia dónde apunta tal imposibilidad, y no la imposibilidad misma. Ya advertía Gadamer que toda afirmación podía ser tomada como la respuesta a una pregunta (y toda pregunta como una respuesta), y que toda pregunta nacía desde un fondo de motivaciones. Lo que ha de ser interpretado siempre está marcado por el marchamo del interrogante, que es lo mismo que decir que está preñado de deseo. “¿Cuál es mi deseo inconsciente?” será la pregunta que inicie cualquier terapia psicoanalítica, aunque no sea formulada explícitamente por el demandante de análisis. “¿Qué me falta y no sé qué es?”, en cualquiera de sus declaraciones encubiertas (sueños, accidentes biográficos, metáforas, síntomas, chistes, anécdotas, actos fallidos y acertados, asociaciones, silencios, fobias, enfados, estornudos, transferencias y luchas con el analista), será lo que al final movilice los elementos que forman esas cadenas inmovilizadas.

En el caso que presentó Leclaire a propósito de la serie de esas puras singularidades inconexas, y que utilizó para mostrarnos el cordón plateado del deseo inconsciente, descubrió a un neurótico obsesivo. Situó el lunar en el cuello fragante de mujer, pero lo relevante no es tal relación inventada, sino el hecho de encontrar un lugar para cada cosa, como les gusta a los obsesivos. Esta casualidad nos hace advertir que es preciso no confundir la presentación de las series lingüísticas para ayudar a localizar el deseo, con la resolución de un caso clínico particular, aunque la resolución de estos casos siempre pasa por descubrir el deseo inconsciente: «si (...) nos damos cuenta de que "lunar", elemento de pura singularidad y radicalmente aislado, no tiene justamente lugar alguno y tiende de hecho-por supuesto que sin lograrlo nunca-a situarse sobre el cuello oloroso, ofreceremos aquí una verdadera interpretación, única capaz de acarrear la solución de la compulsión (...) de este obsesivo» (Leclaire, 2000, p. 190). Queremos subrayar aquí la frase que va entre guiones: el lunar no puede nunca ponerse sobre el cuello, ya que es el psicoanalista quien lo hace para dar paso a la muestra de interés que confiere a este hecho el propio analizado; por eso, la solución es el descubrimiento de la compulsión obsesiva y no la relación entre el lunar y el cuello: el analista no acierta al haber situado el lunar en el cuello, sino por ofrecer al obsesivo un encaje de lugares que celebra y le trae cierto alivio temporal; acierta porque así descubre que es un obse- 
sivo. Esto nos indica que el mundo no tiene un sentido intrínseco, y que somos nosotros quienes se lo damos. El obsesivo sufre por pasarse horas tratando de averiguar de dónde será aquel tornillo que ha encontrado en la alfombrilla del coche, pero su sufrimiento no se detiene ante el hallazgo de la respuesta porque buscaría otras preguntas semejantes. Lo importante no es que el tornillo sea del espejo retrovisor, sino su imposible y estéril esfuerzo por hacer coincidir su ubicación vital como sujeto en un lugar que está condenado a no ocupar nunca porque no existe, aunque él crea que sí. Por eso lo importante no es la pregunta por el vínculo del lunar con el cuello, sino descubrir adónde apunta la pregunta teniendo en cuenta sus motivaciones: la pregunta señala a una falta de nexo, que es casi como decir deseo en estado puro.

¿Quién puede soportar el interrogante de la duda y del vacío de sentido sin dar una respuesta? Hay quienes no pueden soportarlo y por eso se jactan de estar ocupados todo el día, de ser pragmáticos y optimizadores de los beneficios con el mínimo esfuerzo, de no sucumbir ante las tentaciones, de ser expertos en encuadrar cualquier asunto en su lugar preciso, de actuar en función de lo que de ellos se espera, de concretar sus pequeños deseos para saber siempre lo que hay que hacer para conseguirlos. Un retrato así nos habla de alguien que ha renunciado al asombro, al poder del deseo que subyace detrás de esos objetos libres que se esconden en esas cadenas petrificadas o en el valor del significante puro, autónomo y no ligado, modelo lingüístico de la cosa-en-sí kantiana: «un sujeto se asombra precisamente cuando puede soportar el significante. Asombrarse es soportar la carga del significante sin tomarlo inmediatamente como un signo, sin captarlo, sin comprenderlo, porque al comprender se pierde el asombro» (Nasio, 1996, p. 116). Es interesante comprobar cómo esta capacidad de asombro está reñida, al menos en principio, con esa forma de "ser interpretando" que atribuíamos al ser humano; pero consideramos que eso es justamente lo que hace funcionar la actitud hermenéutica, deseo, al fin y al cabo, de salir del atolladero del sinsentido, pues la única manera de no quedarse sepultado bajo el asombro, aunque pueda ser soportado, consiste en tomar algo como algo, en nivelar lo desconocido con lo familiar, que es como renovar la capacidad de sorpresa, la capacidad de permitirnos nuevas experiencias. Para que sea tal, el asombro necesita no prolongarse por tiempo indefinido. Es cierto que al comprender lo perdemos, pero ganamos la posibilidad de otras nuevas y distintas sorpresas.

\section{Un ejemplo a modo de conclusión: lo que falta en el deseo es el nexo}

Para finalizar nos gustaría hacer algunas sugerencias en torno al deseo entendido como falta, pero considerando esa carencia como la ausencia de nexo, y para ello 
emplearemos el argumento de la película 2001: Una odisea del espacio, que nos ayudará a mostrar cómo los efectos de los deseos inconscientes también actúan sobre el consciente. En un mundo como quizá fue el nuestro hace miles de años, como es en la actualidad y como será tal vez en el futuro, aparece una especie de cosa-en-sí: «¿Por qué su color negro?» (Clarke, 1970, p. 71). El mundo es un entramado de referencias hilvanadas por la actividad hermenéutica, una gigantesca red de interpretaciones que no cesa de crecer. "Casi todo" está trabado en cadenas de interpretaciones que posibilitan un empaste coherente de fenómenos, objetos y relaciones: un fémur es usado como arma para defender el territorio (escena de los simios compitiendo por una charca de agua); naves espaciales, ordenadores superpotentes y proyectos científicos que son prótesis o nexos que relacionan al sujeto con el mundo, conformando un fondo de acontecimientos de apropiación donde casi todo tiene significado. $\mathrm{Y}$ aparece el monolito. $\mathrm{Y}$ decimos monolito porque en la película "ello" se tiene que materializar de algún modo; con lo que tenemos un algo que tomamos por un monolito: «era una losa vertical de material como azabache, (...) no presentaba en absoluto ningún detalle de superficie. Resultaba imposible precisar si estaba hecha de piedra, de metal, de plástico... o de algún otro material absolutamente desconocido por el hombre» (Clarke, 1970, p. 62).

¿Qué es y qué relación tiene con todo lo demás? Hay algo que carece de nexo, que destaca su coherencia propia en contraste con la de todo lo demás: ahí tenemos la alteridad radical, lo totalmente otro, la singularidad salvaje por excelencia. $\mathrm{Y}$ ante la inercia hermenéutica, ¿qué se dice del monolito?: «en más de seis horas desde que habia puesto pie en la Luna, Floyd habia oído una docena de teorías» (Clarke, 1970, p. 65). Dios, una formación natural, la caja negra del saber, una roca cósmica de poderes absolutos, un material especial cuyos lados están en relación con los tres primeros números al cuadrado, la cifra del sentido de la vida, un detector de civilizaciones avanzadas puesto por los extraterrestres, el inconsciente colectivo, el significante puro y autónomo..., y todo lo que queramos (como si decimos que es un lunar en un cuello, como en el caso de Leclaire). Algo se muestra para ser tomado por... Es imposible encontrar el hilo, el lazo, la otra parte del als hermenéutico (etwas als etwas). ¿Cómo reacciona la gente ante el monolito?: curiosidad, asombro, adoración, vacío de sentido, deseo obsesivo de encajar la pieza en alguna parte del puzzle cósmico, deseo de saber, deseo de sentido, pero deseo al fin y al cabo; el mismo deseo que pergeñó una base lunar (deseo conseguido), es ahora el que se eleva a la máxima potencia y pureza, es decir, deseo de encontrar el nexo hermenéutico, el otro extremo del als. El verdadero problema no consiste tanto en que la pregunta por el nexo ausente carezca de respuesta, como en la persistencia del estado mental que conduce a formularla, un estado de deseo. Es curioso que cuanta más densidad de nexos y relaciones disfrutamos, la posibilidad de contraste, en el caso de aparecer alguna singularidad exenta de vínculos, se hace también más intensa. 
Sobre un fondo caótico es difícil que algún elemento sobresalga, pero cuando ese fondo adquiere un orden, una configuración, sistematización proporcionada por las labores humanas de interpretación, lo difícil es que algún nódulo quede sin conectar. Ese vacío en la red se muestra más como ausencia en la medida en que abundan a su alrededor los enlaces entre otros nódulos.

\section{Referencias bibliográficas}

AdAm, R. (2007): Lacan y Kierkegaard. (Tr.: V. Ackerman). Nueva Visión. Buenos Aires.

Botella, C. y S. (1997): Más allá de la representación. (Tr.: F.J. Alarcón, I. Agoff, B. Gómez y M. Zubiri). Promolibro. Valencia.

Clarke, A.C. (1970): Una odisea espacial 2001. (Tr.: A. Ribera). Salvat. Madrid.

DAVIDSON, D. (2001): De la verdad y de la interpretación. Fundamentales contribuciones a la filosofia del lenguaje. (Tr.: G. Filippi). Gedisa. Barcelona.

Deleuze, G. (1987): El bergsonismo. (Tr.: L. Ferrero). Cátedra. Madrid.

FErraris, M. (2004): La Hermenéutica. (Tr.: L. Sanz). Cristiandad. Madrid.

Freud, S. (1969): «Autobiografía», en Autobiografía. Historia del movimiento psicoanalítico. (Tr.: L. López-Ballesteros). Alianza Editorial. Madrid.

FREUD, S. (1974): La interpretación de los sueños. (3 vols.). (Tr.: L. LópezBallesteros). Alianza Editorial. Madrid.

FREUD, S. (1993): «Lo inconsciente», en Los textos fundamentales del psicoanálisis. (Tr.: L. López-Ballesteros, R. Rey y G. Dessal). Altaya. Barcelona.

FreUd, S. (1998): «Los sueños», en Introducción al psicoanálisis. (Tr.: L. LópezBallesteros). Altaya. Madrid.

GAdAmer, H.-G. (1981): La razón en la época de la ciencia. (Tr.: E. Garzón Valdés). Alfa. Barcelona.

GadAmer, H.-G. (1994): Verdad y método II. (Tr.: M. Olasagasti). Sígueme. Salamanca.

GADAMER, H.-G. (1997): «La hermenéutica de la sospecha», en ArANZUEQUe, G. (Ed.), Horizontes del relato. Lecturas y conversaciones con Paul Ricoeur. (Tr.: E. López). Departamento de Filosofía de la Facultad de Filosofía y Letras de la Universidad Autónoma de Madrid.

Gadamer, H.-G. (1998): El giro hermenéutico. (Tr.: A. Parada). Cátedra. Madrid.

Gadamer, H.-G. (2000): La herencia de Europa. Ensayos. (Tr.: P. Giralt Gorina). Península. Barcelona.

Gallego López, C. (1996): «Procesamiento del lenguaje metafórico frente al lenguaje literal», Revista de psicología del lenguaje, $\mathrm{N}^{\circ}$. Universidad Complutense de Madrid. 
LeCLAiRe, S. (2000): «La realidad del deseo», en Escritos para el psicoanálisis I. Moradas de otra parte (1954-1993). (Tr.: I. Agoff). Amorrortu. Buenos Aires. LÉvi-Strauss, C. (1970): Tristes trópicos. (Tr.: N. Bastard). Eudeba. Buenos Aires. Lyotard, J.F. (1994): ¿Por qué filosofar? (Tr.: G. González). Altaya. Barcelona.

NAsio, J.D. (1996): El magnifico niño del psicoanálisis. El concepto de sujeto y objeto en la teoría de Jacques Lacan. Gedisa. Barcelona.

Ortega y Gasset, J. (1966): El Espectador. (Tomos III y IV). Espasa-Calpe. Madrid.

PALmeR, R.E. (2002): ¿Qué es la hermenéutica? Teoría de la interpretación en Schleiermacher, Dilthey, Heidegger y Gadamer. (Tr.: B. Domínguez). Arco / Libros. Madrid.

Regnault, F. (1993): Dios es inconsciente. Estudios lacanianos en torno de Santo Tomás de Aquino. (Tr.: I. Bari). Manantial. Buenos Aires.

Ricoevr, P. (1999): Historia y narratividad. (Tr.: G. Aranzueque). Paidós. Barcelona.

Ricoeur, P. (2003): El conflicto de las interpretaciones. Ensayos de hermenéutica. (Tr.: A. Falcón). Fondo de Cultura Económica. Buenos Aires.

SARTRE, J.-P. (1973): Bosquejo de una teoría de las emociones. (Tr.: M. Acheroff). Alianza Editorial. Madrid.

Sperling, D. (2001): Del deseo. Tratado erótico-político. Biblos. Buenos Aires.

José L. Serrano Ribeiro

Universidad Nacional de Educación a Distancia joxelserrano@hotmail.com 